\title{
Impaired breathing, sleeping, vitality, and depression, and negative impact of L-T4 treatment characterize health-related quality of life in older people with stable CVD
}

\author{
Anna K. Ojala ${ }^{1} \cdot$ Harri Sintonen ${ }^{2} \cdot$ Risto P. Roine $^{3,4} \cdot$ Timo E. Strandberg $^{5,6} \cdot$ Camilla Schalin-Jäntti $^{1}$ (D)
}

Received: 27 November 2019 / Accepted: 20 March 2020 / Published online: 10 April 2020

(c) The Author(s) 2020

\begin{abstract}
Background Cardiovascular disease (CVD) and thyroid dysfunction are common in older people, but little is known about how they affect health-related quality of life (HRQoL).

Methods We assessed HRQoL with the 15D instrument in 329 home-dwelling patients aged $\geq 75$ years with stable CVD and compared the results to those of an age- and gender-matched general population $(n=103)$. We also studied the impact of age, BMI, number of medications, thyroid-stimulating hormone (TSH) concentration, levothyroxine (L-T4) substitution and Mini-Mental State Examination (MMSE) on HRQoL.

Results Overall HRQoL was impaired in older people with stable CVD (mean 15D score 0.777 vs $0.801, p=0.001$ ), and also on single dimensions of breathing, sleeping, discomfort and symptoms, distress, vitality (all $p<0.001$ ), and depression $(p=0.016)$ compared to the age- and gender-matched general population. Furthermore, in the patients, L-T4 substitution associated with impaired sleeping $(p=0.018)$ and sexual activity $(p=0.030)$. Moreover, MMSE points, number of medications used, age (all $p<0.001)$ and BMI $(p=0.009)$ predicted impaired HRQoL.

Conclusions Older people with stable CVD are characterized by impaired HRQoL compared to age- and gender-matched controls. We demonstrate that this is the consequence of impaired breathing, sleeping, discomfort and symptoms, distress, vitality, and depression. L-T4 substitution has a negative impact on HRQoL in old patients with stable CVD. MMSE score, number of medications, age and BMI predict worse HRQoL.
\end{abstract}

Keywords HRQoL $\cdot$ CVD $\cdot$ Older people $\cdot$ TSH $\cdot$ L-T4

Camilla Schalin-Jäntti

camilla.schalin-jantti@hus.fi

1 Endocrinology, Abdominal Center, Helsinki University Hospital and University of Helsinki, P.O. Box 340, 00290 Helsinki, Finland

2 Department of Public Health, University of Helsinki, Helsinki, Finland

3 Group Administration, University of Helsinki and Helsinki University Hospital, Helsinki, Finland

4 Department of Health and Social Management, University of Eastern Finland, Kuopio, Finland

5 University of Helsinki, and Helsinki University Hospital, Helsinki, Finland

6 Center for Life Course Health Research, University of Oulu, Oulu, Finland

\section{Introduction}

Cardiovascular disease (CVD) and mild thyroid dysfunction are common in older people. The prevalence of CVD (including coronary heart disease, heart failure, stroke and hypertension) is about $80 \%$ in men and women aged 60-79 years, and further increases with aging to about $90 \%$ in both sexes in individuals aged 80 years or older [1]. Even when hypertension is excluded, the prevalence of CVD in men and women aged 60-79 increases from 18-25 to $34-43 \%$ in individuals over 80 years [1]. Mild thyroid dysfunction is found in over $10 \%$ of older people, and the prevalence of subclinical hypothyroidism, i.e., mildly elevated thyroid-stimulating hormone (TSH) concentrations is even higher, i.e., $21 \%$ in women and $16 \%$ in men aged 74 years or older $[2,3]$. In a recent meta-analysis, in nonpregnant adults with subclinical hypothyroidism, levothyroxine (LT-4) substitution did not improve general quality of life or possible 
thyroid-related symptoms [4]. In cardiovascular trials and studies on CVD, older people are commonly underrepresented [5]. Moreover, longevity itself does not routinely guarantee a good quality of life. Data on how stable CVD or mild thyroid dysfunction affect health-related quality of life (HRQoL) in older individuals is scarce. Previous population-based studies on CVD and HRQoL have been cross-sectional surveys, the focus has not been on older people with CVD, and has not included data on laboratory and clinical examination of the study participants [6-9]. Furthermore, the factors accounting for possible impaired HRQoL have not been identified. We, therefore, wanted to study HRQoL in a cohort of older people ( $>75$ years) with stable CVD with the 15D instrument for assessment, not only of overall HRQoL, but also of 15 different single dimensions, and compare the results to those of an age- and gender-matched general population. Within our cohort of old people with stable CVD, we further assessed the possible relationships of TSH concentrations and L-T4 substitution with HRQoL. We also searched for possible predictors of impaired HRQoL within the patient group.

\section{Design and methods}

\section{Study population and controls}

These are secondary analyses of the prospective Drugs and Evidence Based Medicine in the Elderly (DEBATE) study [10], a geriatrician-internist managed, real-life trial originally aimed at investigating the effect of multifactorial cardiovascular prevention in patients aged 75 years or older with stable CVD. Stable CVD was defined as having prior myocardial infarction, coronary artery disease, peripheral artery disease, previous stroke or transient ischemic attack, from which the patient had recovered. This population-based study consisted of 400 home-dwelling patients aged 75 years or older living in Helsinki, Finland, who were randomly recruited using pre-study mailed questionnaires. All study participants had confirmed CVD, mostly accounted for by coronary heart disease (82\%).

Controls for HRQoL comparisons were obtained from the Finnish National Health 2000 Health Examination Survey [11]. In the original study, a two-stage stratified cluster sampling was performed to obtain a representative cohort of the whole population aged 30 years or older. The age group of 80 or over was oversampled to ensure a sufficient number of older participants, which was also taken into account in the data analysis. Initially, the survey was carried out in different phases, including comprehensive health interviews and examinations, telephone interviews and questionnaires. For the current study, a control population in the age range of the patients and living in the Helsinki University Hospital catchment area was selected and weighted to correspond to the age and gender distribution of the patients.

\section{Measurements}

In older people with stable CVD, clinical status and laboratory parameters (performed with routine methods in the central laboratory of the Helsinki University Hospital) were assessed yearly beginning from year 2000. TSH measurements ( $n=327$; reference range for TSH 0.5-3.6 mU/1 [12]) were performed in 2002. Cognitive performance was evaluated using the Mini-Mental State Examination (MMSE) tool, and The Zung Self-Rating Depression Scale questionnaire for screening of depression. In years 2000 and 2002, HRQoL was assessed with the 15D instrument in 329 of the study subjects $(\mathrm{F} / \mathrm{M}=216 / 113$ aged $82.8 \pm 4.7$ years) and further compared to an age- and gender-matched sample of the general population $(n=103)$. We further compared the HRQoL of the DEBATE study population to the general population adjusting for diabetes, hypertension, myocardial infarction, heart failure, angina, stroke and claudication. Moreover, in the DEBATE cohort, comparisons, adjusted for age, gender, MMSE points and education (primary school or higher), between the 15D scores were made between different TSH ranges $(\mathrm{TSH}<0.5 \mathrm{mU} / \mathrm{l}$; $\mathrm{TSH}=0.5-3.6 \mathrm{mU} / \mathrm{l}$; $\mathrm{TSH}>3.6 \mathrm{mU} / \mathrm{l}$ ), as well as for those on L-T4 substitution compared to those not receiving L-T4 substitution. Finally, in the patient group, the 15D scores recorded in 2000 were compared to the 15D scores measured in 2002. We also searched for possible predictors of HRQoL in patients with stable CVD, such as age, BMI, marital status, level of education, number of medications and MMSE scores.

\section{Mini-mental state examination}

The Mini-Mental State Examination (MMSE), originally developed for assessing cognitive performance in psychiatric patients [13], is commonly used in cognitive function testing among older individuals. The test consists of evaluation of attention, orientation, memory, calculation, recall, registration and visuo-spatial skills scored from 1 to 30 . The cut-off point most commonly used is 24 , lower scores reflecting worse performance. The MMSE is used in clinical practice as a screening test for dementia and also in assessment of suspected dementia. However, although the MMSE contributes to diagnosis of dementia, it is recommended not to be used as a single exclusion or confirmation test of dementia [14].

\section{The Zung self-rating depression scale}

The Zung self-rating depression scale is a 20 -item, selfadministered, Likert scale used for screening of depressive 
symptoms [15]. Each item includes a 4-point scale, ranging from none or a little of the time (1) to most or all of the time (4). For evaluating the severity of depressive symptoms, raw scores (range 20-80) are converted into index scores that range from 25 to 100 . The most conventionally used cut-off point is index score 50, higher index scores indicate more clinically relevant symptoms.

\section{The 15D instrument in assessing health-related quality of life}

The 15D instrument is a generic, well-validated, self-administered tool for measuring HRQoL in individuals aged 16 or older [16]. It consists of 15 dimensions: mobility (move), vision (see), hearing (hear), breathing (breath), sleeping (sleep), eating (eat), speech, excretion (excret), usual activities (uact), mental function (mental), discomfort and symptoms (disco), depression (depr), distress (distr), vitality (vital) and sexual activity (sex). It can be used both as a profile and a single index score measure of HRQoL. Each dimension includes five levels from which the respondent chooses the most appropriate one to describe his/her present health status. For HRQoL assessment, a 15D score is generated over all the dimensions on a $0-1$ scale, higher scores reflecting better HRQoL. The 15D provides a highly reliable, sensitive and generalizable tool for assessing HRQoL and it is also valid for deriving quality-adjusted life years (QALYs) [17-19]. The minimum clinically important cross-sectional difference in the $15 \mathrm{D}$ score is 0.015 [20].

\section{Statistical analyses}

Statistical analyses were performed using SPSS statistical software v. 25.0 (IBM Corp.) by performing independent samples $t$ test and linear regression analyses. For analysis of the correlations, the Pearson correlation coefficient was used. For detection of multicollinearity, tolerance statistics and variance inflation factor (VIF) were investigated. A $p$ value $<0.05$ was considered statistically significant.

\section{Results}

\section{Characteristics of the study subjects}

Clinical and laboratory data of the study subjects according to given TSH ranges ( $\mathrm{TSH}<0.5 \mathrm{mU} / \mathrm{l}$; TSH $=0.5-3.6 \mathrm{mU} / \mathrm{l}$; $\mathrm{TSH}>3.6 \mathrm{mU} / \mathrm{l})$ are presented in Table 1 . There were no significant differences in age, sex, education (primary school or higher), MMSE points or Zung scale distribution between different TSH ranges. Thirty-six subjects $(\mathrm{F} / \mathrm{M}=36 / 0)$ received L-T4 replacement therapy. The number of users was highest within the normal reference range of TSH (TSH $=0.5-3.6 \mathrm{mU} / \mathrm{l})$. Thirty-five percent of subjects with a suppressed TSH $(<0.5 \mathrm{mU} / \mathrm{l})$ were on L-T4. Medication for cognitive disorder was used by four subjects.

\section{HRQoL in old patients with stable CVD compared to the general population}

Overall HRQoL was impaired in old patients with stable CVD compared to the age- and gender-matched general population (mean 15D score 0.777 vs $0.801, p=0.001$; Fig. 1). The observed difference between the mean 15D scores was also clinically important [20]. Significant impairments were observed on the dimensions of breathing, sleeping, discomfort and symptoms, distress, vitality (all $p<0.001$ ), and depression $(p=0.016)$ (Fig. 1). In further analyses, this difference in overall HRQoL disappeared when the findings of the old patients with CVD were adjusted for diabetes,

Table 1 Clinical and laboratory data of older people with stable CVD $(n=327)$ according to different TSH ranges

\begin{tabular}{|c|c|c|c|c|c|}
\hline Variables & $\begin{array}{l}\text { TSH range }<0.5 \mathrm{mU} / 1 \\
(n=20)\end{array}$ & $\begin{array}{l}\text { TSH range } 0.5- \\
3.6 \mathrm{mU} / \mathrm{l}(n=261)\end{array}$ & $\begin{array}{l}\text { TSH range }>3.6 \mathrm{mU} / 1 \\
(n=46)\end{array}$ & $\begin{array}{l}p \text { value between differ- } \\
\text { ent TSH ranges }\end{array}$ & $\begin{array}{l}\text { Total } \\
\text { population } \\
(n=327)\end{array}$ \\
\hline Age, mean (SD) & $82.4(4.9)$ & $82.6(4.8)$ & $83.8(4.7)$ & 0.25 & \\
\hline Women, $n(\%)$ & $15(75)$ & $168(64.4)$ & $32(69.6)$ & 0.53 & $215(65.7)$ \\
\hline Primary school only, $n(\%)$ & $7(36.8)$ & $91(35.0)$ & $24(52.2)$ & 0.085 & $122(37.3)$ \\
\hline BMI & & & & 0.27 & 301 \\
\hline$<25, n(\%)$ & $4(21.1)$ & $94(39.5)$ & $14(31.8)$ & & $112(37.2)$ \\
\hline $25-29, n(\%)$ & $12(63.2)$ & $92(38.7)$ & $19(43.2)$ & & $123(40.9)$ \\
\hline$>29, n(\%)$ & $3(15.8)$ & $52(21.8)$ & $11(25.0)$ & & $66(21.9)$ \\
\hline TSH, mean (SD) & $0.28(1.16)$ & $1.56(1.13)$ & $5.81(1.09)$ & $<0.0001$ & \\
\hline Thyroxin treatment, $n(\%)$ & $7(35.0)$ & $23(8.8)$ & $6(13.0)$ & 0.0013 & $36(11.0)$ \\
\hline MMSE, mean (SD) & $26.1(14.3)$ & $26.6(14.5)$ & $25.4(14.2)$ & 0.85 & \\
\hline Zung, mean (SD) & $36.3(8.9)$ & $37.7(9.7)$ & $38.4(8.8)$ & 0.68 & \\
\hline
\end{tabular}




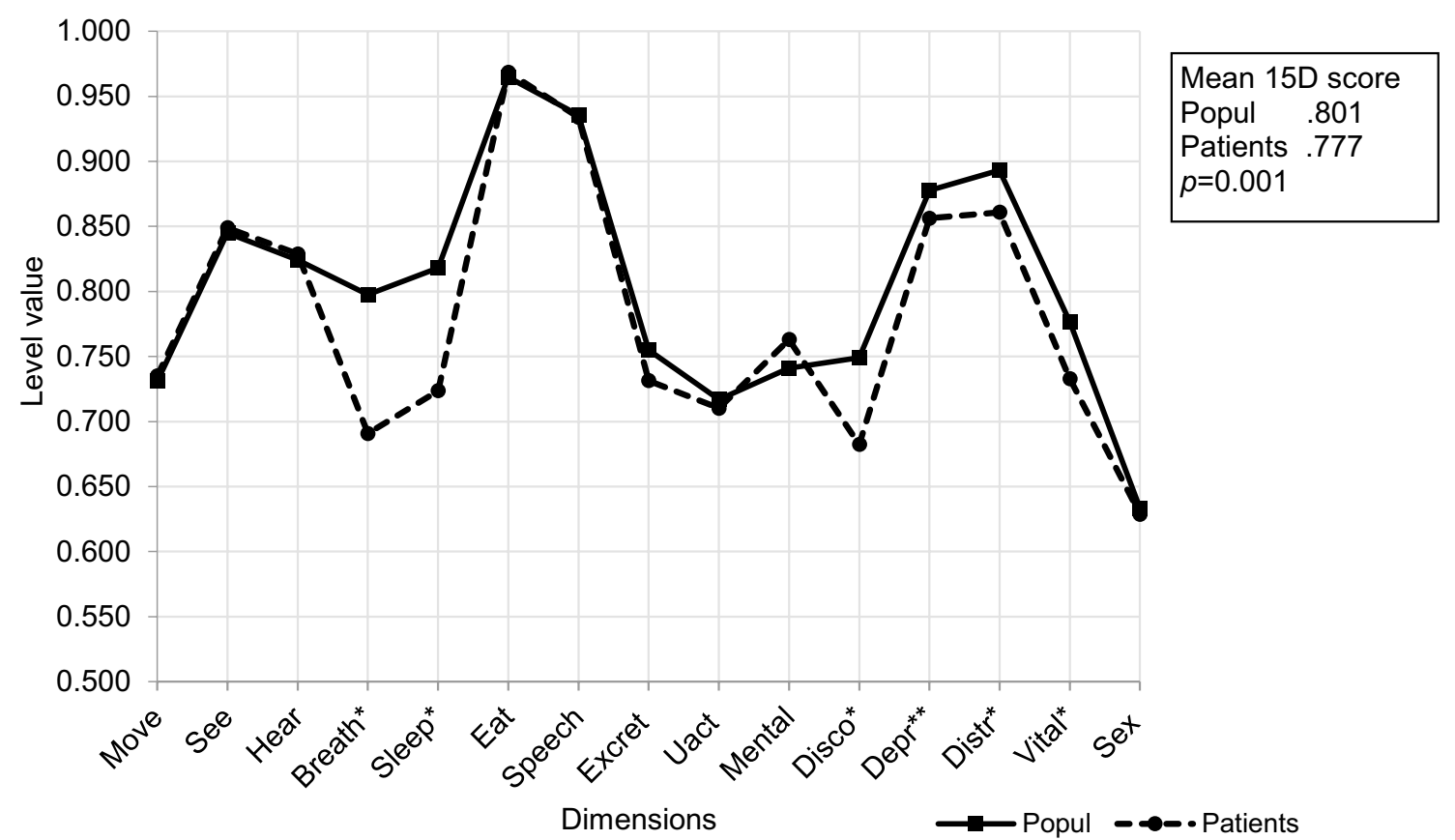

Fig. 1 The mean 15D scores and profiles of old patients with stable CVD $(n=329)$ compared to the age- and gender-matched general population $(n=103)$. Statistically significant differences in $15 \mathrm{D}$

Table 2 Linear regression analysis of variables predicting the $15 \mathrm{D}$ score in older patients with stable CVD

\begin{tabular}{lcr}
\hline Predictor & Regression coefficient & $p$ \\
\hline Constant & 1.149 & $<0.001$ \\
MMSE points $_{\text {Number of medications }}{ }^{\mathrm{a}}$ & 0.009 & $<0.001$ \\
Age & -0.008 & $<0.001$ \\
BMI & -0.005 & $<0.001$ \\
& -0.004 & 0.009 \\
\hline
\end{tabular}

${ }^{a}$ Levothyroxine treatment was not included in the total number of medications, since it was analyzed separately

hypertension, myocardial infarction, heart failure, angina, stroke and claudication ( $p=0.195$, data not shown).

\section{Effect of 2-year aging on HRQOL and predictors of HRQoL in older patients with stable CVD}

Mean 15D score recorded in 2002 did not differ statistically significantly from that obtained in 2000 (data not shown). In linear regression analysis (Table 2), variables predicting the $15 \mathrm{D}$ were MMSE points, number of medications used, age (for all $p<0.001)$ and BMI $(p=0.009)$ (Table 2). The adjusted $R^{2}$ was 0.213 . Sex, marital status, education, TSH level or L-T4 substitution did not influence overall HRQoL (data not shown). Signs of multicollinearity were not detected (data not shown). dimensions between the groups and corresponding $p$ values are indicated with asterisks. $* p<0.001, * * p=0.016$

\section{Relationship between HRQOL and thyroid function in older patients with stable CVD}

No significant differences were found when the mean 15D scores or the single dimensions of HRQoL were compared between different TSH ranges. Subjects on L-T4 scored significantly worse on the dimensions of sleeping $(p=0.018)$ and sexual activity ( $p=0.030)$ (Fig. 2).

\section{Discussion}

We here demonstrate that old people with stable CVD are characterized by impaired HRQoL compared to the general population, and that this is due to impairments in the dimensions of breathing, sleeping, discomfort and symptoms, distress, vitality, and depression. Within the patient group, MMSE points, number of medications, age and BMI turned out as predictors of poorer HRQoL. During a 2-year follow-up, HRQoL remained stable in our cohort, indicating that HRQoL does not deteriorate rapidly in home-dwelling persons $>75$ years. Furthermore, we also found that overall HRQoL is impaired in older people with stable CVD on L-T4 compared to those not on LT-4 therapy, although this was not statistically significant (mean 15D score 0.741 vs $0.782, p=0.051$ ). However, the difference of 0.041 is clinically important, as the minimum clinically important cross-sectional difference for the $15 \mathrm{D}$ score is 0.015 [20]. 


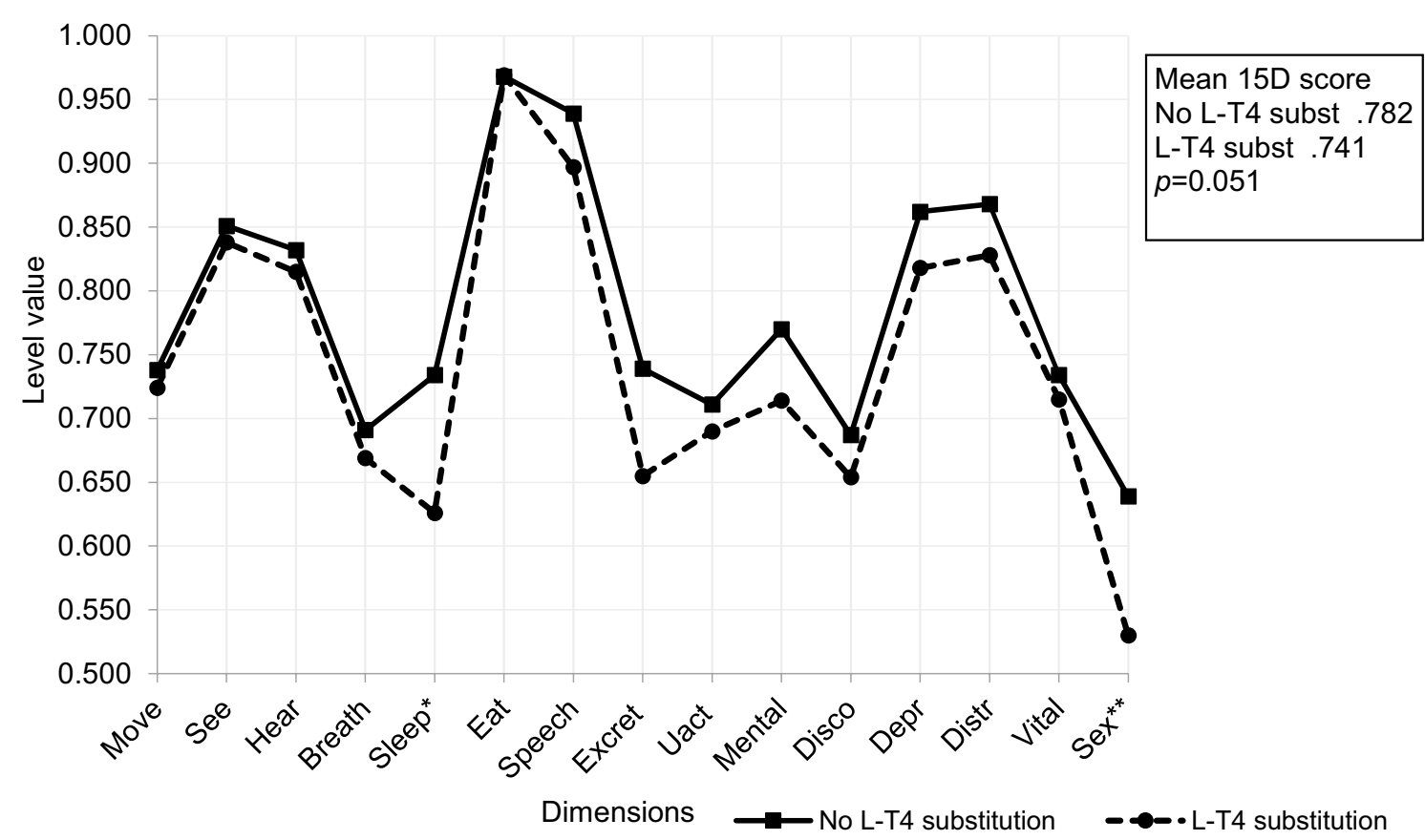

Fig. 2 The mean 15D scores and profiles of patients on L-T4 substitution $(n=36)$ compared to that of subjects having no thyroid medication $(n=323)$. Statistically significant differences in $15 \mathrm{D}$ dimensions

In addition, the dimensions of sleeping and sexual activity were both significantly impaired in subjects on compared to subjects without L-T4 therapy. Thyroxine substitution is thus not associated with improved well-being in older people with stable CVD. Moreover, in the present study, $35 \%$ of old patients with stable CVD characterized by suppressed TSH $(<0.5 \mathrm{mU} / \mathrm{l})$ were on L-T4 therapy, indicating too large a dosing of L-T4.

Multimorbidity is common in older people, ranging from 55 to $98 \%$. Its major consequences are risk of disability, functional decline and poor quality of life [21]. Moreover, the prevalence of both CVD and mild thyroid dysfunction increase with age [1,2]. Our findings are in line with a previous population-based study, where HRQoL was impaired in patients with heart disease (angina, congestive heart failure or heart attack) on the domains of mobility and activities and participation in society compared to those with no prior heart disease, although congestive heart failure was generally associated with the greatest impairments in HRQoL [8]. However, our findings emphasize that in older individuals, stable CVD not only impairs overall HRQoL but also has a negative impact on multiple single dimensions of HRQoL compared to the general population. Of note, in a recent, prospective cohort study of 22,229 adults with no prior CVD, poor HRQoL associated with higher risk of incident CVD events (first non-fatal myocardial infarction (MI), fatal MI or coronary heart disease death, and fatal and non-fatal stroke) [22]. between the groups and corresponding $p$ values are indicated with asterisks. $* p=0.018 * * p=0.030$

Older people are at elevated risk for adverse effects of medication and polypharmacy. A large retrospective cohort study of 52,298 individuals demonstrated falling borderline elevated TSH thresholds for initiating LT-4 therapy as median threshold TSH decreased significantly from 8.7 to $7.9 \mathrm{mU} / \mathrm{l}$ between years 2001 and 2009 [23]. Somewhat surprisingly, the odds ratio for initiating L-T4 when TSH was $\leq 10 \mathrm{mU} / \mathrm{l}$ was highest for older individuals and individuals with cardiac risk factors [23]. This led to suppressed TSH concentrations in $5.8 \%$ of individuals 5 years later, with $\mathrm{TSH}<0.1 \mathrm{mU} / \mathrm{L}$.

Our study revealed that a significant proportion of older people with stable CVD and suppressed TSH $(<0.5 \mathrm{mU} / \mathrm{l})$ received LT-4 substitution. Likewise, in a previous study of patients aged 65 years or older on LT-4 substitution, up to $41 \%$ were characterized by decreased TSH concentrations [24]. According to the 2013 guideline of the European Thyroid Association on management of subclinical hypothyroidism the L-T4 starting dose should be small (25 or $50 \mu \mathrm{g}$ daily) and treatment target for serum TSH higher (up to $5 \mathrm{mU} / \mathrm{l}$ ) in patients with cardiac disease/patients $>70$ years compared to younger subjects not suffering from cardiac disease [25].

In a recent randomized, double-blind, placebo-controlled study of subjects aged 65 years or older with subclinical hypothyroidism, L-T4 substitution was not associated with beneficial effects [26]. There is growing evidence that minor TSH elevations are not associated with impaired quality of 
life, symptoms, cardiovascular events or mortality in older population [27]. Our results are consistent with current recommendations against levothyroxine therapy in asymptomatic older persons with TSH concentrations $<10 \mathrm{mU} / \mathrm{l}$ [28].

Strengths of the study are that it is based on a geriatrician-internist managed, real-life, community-living cohort and that it includes both laboratory and clinical examination of the participants. The rather small control population $(n=103)$ can be regarded as a limitation of the study. However, to increase the specificity of our findings, we wanted to match the controls, not only regarding age- and sex, but also regarding the catchment area. This decreased the number of controls. However, as significant differences between the patient and the control population were found both in the total 15D score as well as in several single dimension scores, the findings would probably have been even stronger had the control population been larger.

\section{Conclusions}

Compared to the age- and gender-matched general population, overall HRQoL and the dimensions of breathing, sleeping, discomfort and symptoms, distress, vitality, and depression are impaired in 75+ people with stable CVD. Levothyroxine substitution has a negative impact on HRQoL in older patients with stable CVD.

Acknowledgements Open access funding provided by University of Helsinki including Helsinki University Central Hospital.

Author contributions All authors contributed to the study conception and design. Material preparation, data collection and analysis were performed by AKO, TES and HS. The first draft of the manuscript was written by AKO. AKO and CS-J wrote the second version. All authors commented on the next versions of the manuscript. All authors read and approved the final manuscript, and contributed to the revision of the manuscript.

Funding This work was supported by Finska Läkaresällskapet (to 2018/AKO/CS-J), grants from the Helsinki University Hospital Research Funds (TYH2017138 and TYH2018223, to CS-J).

\section{Compliance with ethical standards}

Conflict of interest Harri Sintonen is the developer of the 15D and obtains royalties from its electronic versions. The other authors declare that they have no conflicts of interest.

Ethical approval All procedures performed in studies involving human participants were in accordance with the ethical standards of the institutional and/or national research committee and with the 1964 Helsinki Declaration and its later amendments or comparable ethical standards. All stages of the DEBATE study have been approved by the Ethics Committee of the Department of Medicine, University of Helsinki (in 1999).
Research involving human participants and/or animals All procedures performed in studies involving human participants were in accordance with the ethical standards of the institutional and/or national research committee and with the 1964 Helsinki Declaration and its later amendments or comparable ethical standards.

Informed consent Informed consent according to the Declaration of Helsinki was obtained from all patients before any study procedures, which are performed according to good clinical trial practice.

Open Access This article is licensed under a Creative Commons Attribution 4.0 International License, which permits use, sharing, adaptation, distribution and reproduction in any medium or format, as long as you give appropriate credit to the original author(s) and the source, provide a link to the Creative Commons licence, and indicate if changes were made. The images or other third party material in this article are included in the article's Creative Commons licence, unless indicated otherwise in a credit line to the material. If material is not included in the article's Creative Commons licence and your intended use is not permitted by statutory regulation or exceeds the permitted use, you will need to obtain permission directly from the copyright holder. To view a copy of this licence, visit http://creativecommons.org/licenses/by/4.0/.

\section{References}

1. Benjamin EJ, Muntner P, Alonso A et al (2019) Heart disease and stroke statistics-2019 update: a report from the American Heart Association. Circulation 139:e56-e528. https://doi.org/10.1161/ CIR.0000000000000659

2. Canaris GJ, Manowitz NR, Mayor G et al (2000) The Colorado thyroid disease prevalence study. Arch Intern Med 160:526-534

3. Ruggeri RM, Trimarchi F, Biondi B (2017) Management of endocrine disease: 1-thyroxine replacement therapy in the frail elderly: a challenge in clinical practice. Eur J Endocrinol 177:R199-R217. https://doi.org/10.1530/EJE-17-0321

4. Feller M, Snel M, Moutzouri E et al (2018) Association of thyroid hormone therapy with quality of life and thyroid-related symptoms in patients with subclinical hypothyroidism: a systematic review and meta-analysis. JAMA 320:1349-1359. https://doi. org/10.1001/jama.2018.13770

5. Rich MW, Chyun DA, Skolnick AH et al (2016) Knowledge gaps in cardiovascular care of older adults: a scientific statement from the American Heart Association, American College of Cardiology, and American Geriatrics Society: executive summary. J Am Geriatr Soc 64:2185-2192. https://doi.org/10.1111/jgs.14576

6. Stafford M, Soljak M, Pledge V et al (2012) Socio-economic differences in the health-related quality of life impact of cardiovascular conditions. Eur J Pub Health 22:301-305. https://doi. org/10.1093/eurpub/ckr007

7. González-Chica DA, Adams R, Dal Grande E et al (2017) Lower educational level and unemployment increase the impact of cardiometabolic conditions on the quality of life: results of a population-based study in South Australia. Qual Life Res 26:1521-1530. https://doi.org/10.1007/s11136-017-1503-y

8. Manuel DG, Leung M, Nguyen K et al (2003) Burden of cardiovascular disease in Canada. Can J Cardiol 19:997-1004

9. Tran BX, Moir MP, Thai TPT et al (2018) Socioeconomic inequalities in health-related quality of life among patients with cardiovascular diseases in Vietnam. Biomed Res Int 2018:1-8. https ://doi.org/10.1155/2018/2643814

10. Strandberg TE, Pitkala KH, Berglind S et al (2006) Multifactorial intervention to prevent recurrent cardiovascular events in patients 
75 years or older: the Drugs and Evidence-Based Medicine in the Elderly (DEBATE) study: a randomized, controlled trial. Am Heart J 152:585-592. https://doi.org/10.1016/j.ahj.2006.02.006

11. Aromaa A, Koskinen S (eds) (2004) Health and functional capacity in Finland. Baseline results of the health 2000 Health Examination Survey. Publications of the National Public Health Institute B12, Helsinki

12. Schalin-Jantti C, Tanner P, Valimaki MJ et al (2000i) Serum TSH reference interval in healthy Finnish adults using the Abbott Architect 2000i Analyzer. Scand J Clin Lab Invest 71:344-349. https://doi.org/10.3109/00365513.2011.568630

13. Folstein MF, Folstein SE, McHugh PR (1975) "Mini-mental state". A practical method for grading the cognitive state of patients for the clinician. J Psychiatr Res 12:189-198. https://doi. org/10.1016/0022-3956(75)90026-6

14. Creavin ST, Wisniewski S, Noel-Storr AH et al (2016) MiniMental State Examination (MMSE) for the detection of dementia in clinically unevaluated people aged 65 and over in community and primary care populations. Cochrane Database Syst Rev. https ://doi.org/10.1002/14651858.CD011145.pub2

15. Zung WWK (1965) A self-rating depression scale. Arch Gen Psychiatry 12:63-70. https://doi.org/10.1001/archpsyc.1965.01720 310065008

16. Sintonen H (2001) The $15 \mathrm{D}$ instrument of health-related quality of life: properties and applications. Ann Med 33:328-336

17. Romskaug R, Skovlund E, Straand J et al (2019) Effect of clinical geriatric assessments and collaborative medication reviews by geriatrician and family physician for improving health-related quality of life in home-dwelling older patients receiving polypharmacy: a cluster randomized clinical trial. JAMA Intern Med. https://doi.org/10.1001/jamainternmed.2019.5096

18. Salminen KS, Suominen MH, Soini H et al (2019) Associations between nutritional status and health-related quality of life among long-term care residents in Helsinki. J Nutr Health Aging 23:474478. https://doi.org/10.1007/s12603-019-1182-1

19. Perttila NM, Pitkala KH, Kautiainen $\mathrm{H}$ et al (2017) Various diagnostic measures of frailty as predictors for falls, weight change, quality of life, and mortality among older Finnish men. J Frailty Aging 6:188-194. https://doi.org/10.14283/jfa.2017.26
20. Alanne S, Roine RP, Rasanen P et al (2015) Estimating the minimum important change in the 15D scores. Qual Life Res 24:599606. https://doi.org/10.1007/s11136-014-0787-4

21. Marengoni A, Angleman S, Melis R et al (2011) Aging with multimorbidity: a systematic review of the literature. Ageing Res Rev 10:430-439. https://doi.org/10.1016/j.arr.2011.03.003

22. Pinheiro LC, Reshetnyak E, Sterling MR et al (2019) Using health-related quality of life to predict cardiovascular disease events. Qual Life Res 28:1465-1475. https://doi.org/10.1007/ s11136-019-02103-1

23. Taylor PN, Iqbal A, Minassian C et al (2014) Falling threshold for treatment of borderline elevated thyrotropin levels-balancing benefits and risks: evidence from a large community-based study. JAMA Intern Med 174:32-39. https://doi.org/10.1001/jamaintern med.2013.11312

24. Somwaru LL, Arnold AM, Joshi N et al (2009) High frequency of and factors associated with thyroid hormone over-replacement and under-replacement in men and women aged 65 and over. J Clin Endocrinol Metab 94:1342-1345. https://doi.org/10.1210/ jc.2008-1696

25. Pearce SH, Brabant G, Duntas LH et al (2013) 2013 ETA guideline: management of subclinical hypothyroidism. Eur Thyroid J 2:215-228. https://doi.org/10.1159/000356507

26. Stott DJ, Rodondi N, Kearney PM et al (2017) Thyroid hormone therapy for older adults with subclinical hypothyroidism. N Engl J Med 376:2534-2544. https://doi.org/10.1056/NEJMoa1603825

27. Leng O, Razvi S (2019) Hypothyroidism in the older population. Thyroid Res 12:2-3. https://doi.org/10.1186/s13044-019-0063-3

28. Bekkering GE, Agoritsas T, Lytvyn L et al (2019) Thyroid hormones treatment for subclinical hypothyroidism: a clinical practice guideline. BMJ 365:12006. https://doi.org/10.1136/bmj.12006

Publisher's Note Springer Nature remains neutral with regard to jurisdictional claims in published maps and institutional affiliations. 